\title{
The comparison of balance and leg muscle strength between tai chi and yoga in older adults: A cross-sectional study
}

Authors' Contribution: A Study Design B Data Collection C Statistical Analysis D Data Interpretation E Manuscript Preparation F Literature Search G Funds Collection

\author{
Mentari A. Jelita ABDFG, Julia R. Tanjung ABEF, Ignatio R. Haryono CDEF, \\ Nawanto A. Prastowo BCDEF \\ Department of Physiology, School of Medicine \& Health Sciences, \\ Atma Jaya Catholic University of Indonesia, Jakarta, Indonesia
}

\section{abstract}

Background:

Material and methods:

Results: One-way ANOVA showed a difference in LMS and SLS between groups $(p<0.01)$. LSD post hoc analysis found the difference in LMS between tai chi and yoga ( 64.3 vs. $41.5, p<0.01)$ and tai chi and control $(64.3$ vs. $30.4, p<0.01)$. The difference was also found in SLS between tai chi and control $(36.7$ vs. $6.2, p<0.01)$ and between yoga and control (41.4 vs. $6.2, p<0.01)$.

Conclusions: Elderly persons who participated in tai chi and yoga demonstrated higher LMS and SLS performance than the sedentary participants. The tai chi group showed better muscle strength than the yoga group

Key words: elderly, exercise, risk of falls, leg muscle strength, balance.

\section{article details}

Article statistics: Word count: 2,263; Tables: 2; Figures: 2; References: 20

Received: August 2020; Accepted: May 2021; Published: September 2021

Full-text PDF: http://www.balticsportscience.com

Copyright @ Gdansk University of Physical Education and Sport, Poland

Indexation: Celdes, Clarivate Analytics Emerging Sources Citation Index (ESCI), CNKI Scholar (China National Knowledge Infrastructure), CNPIEC, DOAJ, EBSCO - Central \& Eastern European Academic Source, EBSCO - SPORTDiscus, EBSCO Discovery Service, Google Scholar, Index Copernicus, J-Gate, Naviga (Softweco, Primo Central (ExLibris), ProQuest - Family Health, ProQuest - Health \& Medical Complete, ProQuest - Illustrata: Health Sciences, ProQuest Nursing \& Allied Health Source, Summon (Serials Solutions/ProQuest, TDOne (TDNet), Ulrich's Periodicals Directory/ ulrichsweb, WorldCat (OCLC)

Funding: This research received no specific grant from any funding agency in the public, commercial, or not-for-profit sectors.

Conflict of interests: Corresponding author:

Open Access License:
Authors have declared that no competing interest exists.

Nawanto A. Prastowo, Department of Physiology, School of Medicine \& Health Sciences, Atma Jaya Catholic University of Indonesia, Jakarta, Indonesia; e-mail: nawanto.agung@atmajaya.ac.id; phone +62(021) 6693168, fax +62(021) 6606123

This is an open access article distributed under the terms of the Creative Commons Attribution-Non-Commercial-NoDerivatives 4.0 International (https://creativecommons.org/licenses/by-nc-nd/4.0/), which permits use, distribution, and reproduction in any medium, provided the original work is properly cited, the use is non-commercial and is otherwise in compliance with the license. 


\section{INTRODUCTION}

Increasing numbers of older people have become a global phenomenon in the 21 st century [1]. This may be caused by an improvement in the health status and life expectancy due to advances in medicine. Consequently, this will increase degenerative diseases due to the aging process, which results in some significant changes in functional capacity, notably decreased balance and muscle strength [2, 3]. Decreased balance and muscle strength are significant in increasing the fall accident, which is considered as one of the main predictors of death in older adults $[1,2]$.

Falls are a serious health problem in the elderly because more than $25 \%$ of people over 65 years of age experience falls each year, and for more than $50 \%$ they are recurrent [3-5]. Falls can cause adverse effects that threaten the safety and independence of the elderly, including injuries, fractures, disabilities, brain damage, irreversible secondary complications, and even death [6]. However, falls in the elderly are preventable. Several studies reported that improving the balance and leg muscle strength in the elderly can significantly reduce falls $[3,6,7]$.

Tai chi has become more popular and widely recommended as an exercise to improve balance and prevent falls in older adults [5]. The increasing participation in tai chi among the elderly is associated with feasibility (comfortable, inexpensive, fun) and benefits, both physical and psychological. Several studies have observed that tai chi effectively improves cognitive functioning, cardiovascular conditions, pain syndromes, osteoarthritis, Parkinson's disease, asthma, and mainly prevents falls in older adults [6-9]. Tai chi consistently shows excellent benefits in decreasing the risk of falls, typically associated with improvements in static and dynamic balance [6, 9]. According to Hakim et al., tai chi promotes more exceptional dynamic balance ability as participants continuously shift their weight over a moving base of support [4]. The literature on tai chi also reported the effectiveness of tai chi in increasing leg muscle strength [8]. The dynamic characteristics of tai chi movements can cause mechanical movements that elicit loading, pressure, and tension on the legs that stimulate bone formation and muscle mass [8]. Also, it was reported that people who practice tai chi have better reaction time and antagonistic muscle contractions $[5,8]$.

Yoga represents a body practice that may include postures, breathing exercises, meditation, lifestyle changes, and spiritual beliefs [10]. Yoga is characterized by specific movements that are maintained for a long time. Yoga's beneficial effects have been reported, such as improving balance, muscle strength, endurance, flexibility, gait, and mental health status $[4,6,11,12]$. However, fewer elderly persons practice yoga than tai chi [4, 11]. A study regarding yoga's perceptions among the elderly reported that the elderly anticipated that they would struggle with yoga because they find yoga movements challenging and requiring specific skills [12]. Also, the elderly have less information on what types of yoga are suitable for them and they are concerned about the possibility of injury in yoga as reported at 8-fold for those aged 65 years or older [12, 13]. These might become contributing factors regarding the scarcity of studies conducted on the effects of yoga on the elderly [11]. Although tai chi and yoga have different characters, only few studies compare physical benefits of these exercises $[4,6,8]$. Thus, the purpose of this study is to compare the balance performance and leg muscle strength between tai chi and yoga practitioners among the elderly.

\section{MATERIAL AND METHODS}

This study was a cross-sectional. Purposive sampling methods was applied. Ninety participants aged 60 or older were eligible. The three groups of participants were the tai chi group $(n=36)$, the yoga group $(n=23)$, and the control group $(n=31)$. The control 
group consisting of those who did not participate in any exercise. Inclusion criteria were set as follows: practicing tai chi or yoga at least twice a week for at least three months, BMI $25 \mathrm{~kg} / \mathrm{m}^{2}$ or less, community-dwelling. Participants were excluded if they were on medication that affected balance and muscle strength, had severe organ dysfunction in the brain, vision, hearing, musculoskeletal, limb injury, or participated in another exercise regularly or had difficulty communicating. A questionnaire was used to obtain the inclusion and exclusion criteria.

Participants in the yoga group practiced adapted yoga for senior programs. The adapted programs for seniors focused more on maintaining physical performance and injury prevention in the elderly. Movements and poses of yoga in these programs were seniorfriendly and considered gentle, less intense, non-arduous, focused more on muscle stretching, flexibility, and breathing techniques.

All participants gave their written informed consent before participation. The Ethics Committee of School of Medicine \& Health Sciences, Atma Jaya Catholic University of Indonesia, approved the study (No:19/07/KEP-FKUAJ/2019).

Height was measured in a standing position barefoot using a stadiometer, expressed in $\mathrm{cm}$. Weight was measured using a digital scale (Robusta 813, Seca, Germany) in minimal clothes, presented in $\mathrm{kg}$. BMI was calculated by dividing weight $(\mathrm{kg})$ by a square of height $(\mathrm{m})$, expressed in $\mathrm{kg} / \mathrm{m}^{2}$.

Muscle strength was assessed by measuring the leg muscle strength (LMS) using a back muscle dynamometer (T.K.K.5402 from Takei Scientific Instruments Co., LTD, Japan). The participants stood on a support platform with their leg semiflexed at $150^{\circ}$, trunk in the upright position. Both hands grasped the handle attached to the dynamometer using adjustable chains. The participants were instructed to extend their legs for 3 seconds without releasing their grasp in upright position [14]. The participants performed three trials with 60 -seconds rest between trials. The maximum value of the trials was recorded for analysis.

Single leg stance (SLS) test was performed by standing on one leg without assistance with their eyes open while both arms were resting on the hips. The test was initiated when the subject started to lift one leg while flexing the knee and ended when the subject dropped the lifted leg. The participants had to maintain this position for as long as possible, or the test would stop when it reached sixty seconds. The examiner stood beside the participant during the test to guard them against falling. The SLS test was carried out three times, and the highest score of their three attempts was recorded. Participants were allowed to take a rest for 1-2 minutes between the trials. The results of SLS .denoted as 'good' if 60 seconds or more and as 'poor' if less than 60 seconds. This test is valid and reliable, with validity ranging between $0.657-0.998$ and reliability of 0.84-0.97 [15].

A Chi-square test was used to assess gender distribution between groups. The Spearman rank correlation test was applied to evaluate the distribution of SLS classification between the groups. One-way ANOVA was employed to compare numeric variables between the groups. The Least Significant Difference (LSD) test was a post hoc test to examine which groups were different. The significance was set at $p<0.05$. The statistical test was computed using IBM SPSS software version 19.0 (Chicago, Illinois).

\section{RESULTS}

The participants' characteristics are presented in Table 1. There were more females than males in the study, with an average age of above 65 years. The average BMI is at an overweight limit for Asians. Most of the participants had poor SLS results (65/72.2\%). 
Table 2 shows a comparison of variables between the groups, according to one-way ANOVA. The Chi-square test showed that there were significantly more female participants in the control group ( $p=0.046$ ). One-way ANOVA found differences in LMS and SLS between the groups $(p<0.01)$. The LSD post-hoc analysis demonstrated that LMS differences existed between yoga and tai chi $(p<0.01)$ and control and tai chi $(p<0.01)$ (Fig. 1). In SLS, the difference was found between yoga and control $(p<0.01)$ and tai chi and control $(p<0.01)$ (Fig. 2$)$.

Table 1. The participants' characteristics

\begin{tabular}{lc} 
Characteristics & Mean \pm SD or frequency \\
\hline Gender & \\
Females (n) & $67(74.4 \%)$ \\
Males (n) & $23(25.6 \%)$ \\
Age (ears) & $67.5 \pm 5.3$ \\
Weight (kg) & $60.0 \pm 8.8$ \\
Height (cm) & $160.1 \pm 6.9$ \\
BMI (kg/m²) & $23.3 \pm 2.4$ \\
LMS (kg) & $47.3 \pm 25.8$ \\
SLS (seconds) & $27.8 \pm 23.7$ \\
SLS category & \\
Good & $25(27.8 \%)$ \\
Poor & $65(72.2 \%)$ \\
\hline
\end{tabular}

BMI - body mass index; LMS - leg muscle strength; SLS - single leg stand.

Table 2. The comparison of variables between groups

\begin{tabular}{lcccc} 
Characteristics & Control & Tai Chi & Yoga & $p$ \\
\hline Gender & & & & 0.046 \\
$\quad$ Females (n) & 27 & 22 & 18 & \\
$\quad$ Males (n) & 4 & 14 & 5 & 0.135 \\
Age (ears) & $69.0 \pm 5.1$ & $66.7 \pm 4.9$ & $66.7 \pm 5.8$ & 0.111 \\
Weight (kg) & $58.9 \pm 8.5$ & $62.5 \pm 9.0$ & $57.9 \pm 8.2$ & 0.201 \\
Height (cm) & $159.2 \pm 5.3$ & $161.8 \pm 8.4$ & $158.8 \pm 5.6$ & 0.316 \\
BMI (kg/m ${ }^{2}$ ) & $23.2 \pm 2.4$ & $23.8 \pm 2.2$ & $22.9 \pm 2.4$ & $<0.01$ \\
LMS (kg) & $30.4 \pm 16.5$ & $64.3 \pm 26.7$ & $41.5 \pm 16.3$ & $<0.01$ \\
SLS (seconds) & $6.2 \pm 6.1$ & $36.7 \pm 21.5$ & $41.4 \pm 22.4$ & $<0.01$ \\
SLS category & & & & 13 \\
$\quad$ Good & - & 12 & 10 & \\
$\quad$ Poor & 31 & 24 & & \\
\hline
\end{tabular}

BMI - body mass index; LMS - leg muscle strength; SLS - single leg stand.

LMS (kg)

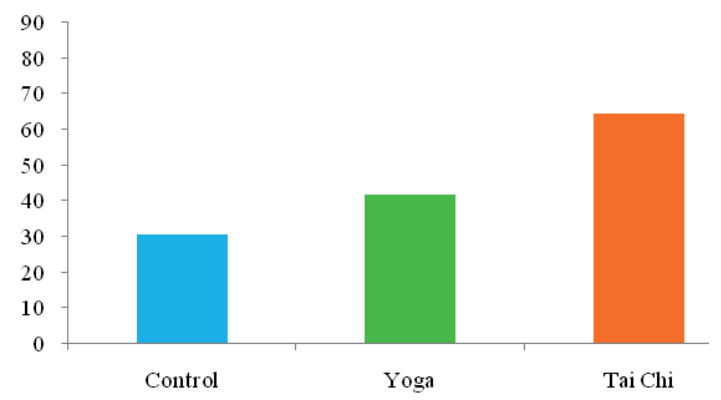

Fig. 1. Comparison of LMS between groups by post-hoc analysis (LMS - leg muscle strength) 


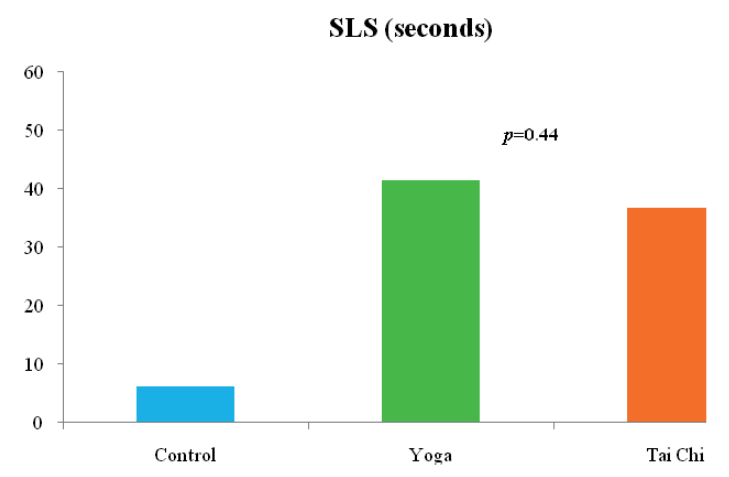

Fig. 2. Comparison of SLS between groups by post-hoc analysis (SLS - single leg stand)

\section{DISCUSSION}

The beneficial effect of exercise for the elderly has been recognized. Nevertheless, fewer studies revealed the benefits of tai chi and yoga on muscle strength and balance in the elderly. This study observed that elderly persons practicing tai chi or yoga have significantly stronger leg muscles and better balance than those who did not exercise. It was hypothesized that the elderly who participate in physical activities focusing on coordination training and balance, such as tai chi and yoga, tend to maintain or enhance the overall balance function. Exercise may affect many balance components in older adults, such as proprioceptive sensory aspects, gait, and muscle strength [2, 5, 8, 15]. Hakim et al. and Ni et al. also support this statement. They concluded that the elderly would experience physiologically decreased organ function, such as the somatosensory function, the vestibular system, visual, peripheral sensations, muscle weakness, also increased in muscle response time $[4,5]$. However, balance training in the elderly can enhance the balance control component, which will lower the risk of falling.

The balance between tai chi and yoga with control significantly differs. This might occur because tai chi and yoga target a better balance output. Although these exercises use distinctive methods, they have a similar effect and balance. A review study stated that tai chi was effective in enhancing the balance function, both static and dynamic [16]. An intervention study by Hosseini et al. observed that tai chi for eight weeks improves balance and a fear of falling as assessed with some assessment tools [17]. A study in India investigated the effect of yoga exercises on balance [19]. The study observed that practising yoga for three months enhances balance and mobility in the elderly as evaluated by physical performance tests [19]. These results were similar to our findings. We included similar participants' characteristics and exercise duration.

Tai chi and yoga are considered to be able to affect all components of balance. However, the mechanism may be distinct. Tai chi or yoga may have a more dominant impact on one component. For instance, yoga movements increase the sensory component of balance (proprioception system) more than tai chi [10]. Nevertheless, at the same time, yoga also enhances the motor component (strength and flexibility), though it is not better than tai chi. While movements in tai chi increase the motor component of balance (leg muscle strength and muscle response) better than yoga, tai chi provides lower proprioceptive input than yoga $[4,9]$. An improvement in one component of balance will have an impact on overall balance. Hakim et al. also found the same result in their research. They concluded that there was no statistical difference between balance in tai chi and yoga [4].

The SLS test indicated that either the tai chi or yoga group had significantly better balance than the control group than the control group. However, even though no statistical 
differences in SLS between tai chi and yoga, the yoga group performed SLS a little better than the tai chi group. This may occur because yoga is usually conducted barefoot on a less stable surface, such as a mat or sand, whereas tai chi is commonly performed on more stable, flat, harder surfaces, such as floor tile or ground. Practicing on less stable surface in yoga may increase the body's vagal activity. Field shows that balance of older adults who follow yoga increases due to stimulation via dermal/subdermal pressure receptors maintained by afferent vagal nerve fibers [10]. Consequently, this increases the sensory component of one's proprioceptive system. Takeshima et al. also discussed that balance exercises performed on unstable surfaces (such as foam pads/mattresses) increased the demand for someone to change and control their body's support better. Therefore, the SLS results of tai chi groups that are slightly lower than yoga may be due to the tai chi's less provoking instability to their body's support than yoga [7].

The leg muscle strength of the tai chi and yoga groups was greater than in the control group. Stronger leg muscle due to exercise balance can maintain and even increase leg muscle mass and strength in the elderly. Elderly persons who do not participate in exercise will lose their muscle tone, strength, and flexibility. This leads to decreased balance, which is a predisposing factor for falls $[1,3,4]$. Taylor et al. stated that older adults who participated in tai chi and yoga had better leg muscle strength than those who did not exercise [20]. There was a significant difference in the LMS results in tai chi compared to yoga and control groups. We highlighted the significant difference in LMS between Tai hi and yoga. Older adults who participated in tai chi showed greater muscle strength than in the yoga group. This may happen because the movements of tai chi are continuous and dynamic to change the support of body weight, which will create a better dynamic balance ability $[5,8,20]$.

\section{LIMITATIONS}

Limitations of this study are noted. First, a cross-sectional nature of the study could not determine a significant direct effect of the exercises on LMS and SLS performance so that the change in LMS and SLS before-after exercise could not be seen. Second, participants live in a similar typical environment, including cultural and social settings, which might influence the results. Third, tai chi and yoga were compared with conventional exercises such as walking or jogging to examine the difference in magnitude of the effect on LMS and SLS and feasibility between those exercises.

\section{CONCLUSION}

This study concludes that tai chi and yoga improve balance and leg muscle strength and may prevent falls in the elderly. Yoga improves SLS more significantly, while tai chi enhances LMS more prominently. However, this finding should be interpreted carefully due to some limitations. We recommend that health care providers and practitioners consider tai chi and yoga to maintain or improve balance and leg muscle strength in the elderly.

\section{ACKNOWLEDGMENTS}

The authors thank all respondents who have participated in this study. We also thank Mr. Djoko, Mrs. Rita, Mr. Stephen, Ms. Eva, and Mrs.Veronika for managing the subjects.

\section{REFERENCES}

[1] Organization WH. World report on aging and health: World Health Organization; 2015.

[2] Noohu MM, Dey AB, Hussain ME. Relevance of balance measurement tools and balance training for fall prevention in older adults. J Clin Gerontol. 2014;5(2):31-5. https://doi.org/10.1016/j.jcgg.2013.05.002 
[3] Cho SI, An DH. Effects of a fall prevention exercise program on muscle strength and balance of the old-old elderly. J Phys Ther Sci. 2014;26(11):1771-1774. https://doi.org/10.1589/jpts.26.1771

[4] Hakim R, Kotroba E, Cours J, Teel S, Leininger P. A cross-sectional study of balance-related measures with older adults who participated in tai chi, yoga, or no exercise. Phys Occup Ther Geriatr. 2010;28(1):63-74. https://doi. org/10.3109/02703181003605861

[5] Ni M, Mooney K, Richards L, Balachandran A, Sun M, Harriell K, et al. Comparative impacts of tai chi, balance training, and a specially-designed yoga program on balance in older fallers. Arch Phys Med Rehab. 2014;95(9):1620-1628. https://doi.org/10.1016/j.apmr.2014.04.022

[6] Saravanakumar P, Johanna Higgins I, Jane van der Riet P, Marquez J, Sibbritt D. The influence of tai chi and yoga on balance and falls in a residential care setting: a randomized controlled trial. Contemp Nurse. 2014;48(1):76-87. https://doi.org/10.1080/10376178.2014.11081929

[7] Takeshima N, Islam M, Kato Y, Koizumi D, Narita M, Rogers N, et al. Effects of 12 weeks of tai chi chuan training on balance and functional fitness in older Japanese adults. Sports. 2017;5(2):32. https://doi.org/10.3390/sports5020032

[8] Field T. Tai Chi research review. Complement Ther Clin Pract. 2011;17(3):141-146. https://doi.org/10.1016/j. ctcp.2010.10.002

[9] Huston P, McFarlane B. Health benefits of tai chi: What is the evidence? Can Fam Physician. 2016;62(11):881-890

[10] Birdee GS, Legedza AT, Saper RB, Bertisch SM, Eisenberg DM, Phillips RS. Characteristics of yoga users: Results of a national survey. J Gen Intern Med. 2008;23(10):1653-1658. https://doi.org/10.1007/s11606-008-0735-5

[11] Field T. Yoga clinical research review. Complement Ther Clin Pract. 2011;17(1):1-8. https://doi.org/10.1016/j. ctcp.2010.09.007

[12] Sivaramakrishnan D, Fitzsimons C, Mutrie N, Baker, G. Perceptions of yoga among older adults: A qualitative approach. Ann Yoga Physic Ther. 2017;2(4):1-8.

[13] Swain TA, McGwin G. Yoga-related injuries in the United States from 2001 to 2014. Orthopaedic J Sports Med. 2016;4(11):1-6. https://doi.org/10.1177/2325967116671703

[14] Alfonso Castillo-Rodríguez, Wanesa Onetti-Onetti, Rui Sousa Mendes, José Luis Chinchilla-Minguet. Relationship between leg strength and balance and lean body mass. Benefits for active aging. Sustainability. 2020;12:1-9, 2380; https://doi.org/10.3390/su12062380

[15] Navalta JW, Stone WJ, Lyons S. Ethical issues relating to scientific discovery in exercise science. Int J Exerc Sci. 2019;12(1):1-8

[16] Perez-Cruzado D, González-Sánchez M, Cuesta-Vargas AI. Parameterization and reliability of single-leg balance test assessed with inertial sensors in stroke survivors: a cross-sectional study. BioMed Eng OnLine 2014;13:127. https:// doi.org/10.1186/1475-925X-13-127

[17] Wong AMK, Lan C. Tai Chi, and balance control. Med Sport Sci. 2008;52:115-123. https://doi.org/10.1159/000134291

[18] Hosseini L, Kargozar E, Sharifi F, Negarandeh R, Memari AH, Navab E. Tai Chi Chuan can improve balance and reduce the fear of falling in community dwelling older adults: Aa randomized control trial. J Exerc Rehabil. 2018; 14(6):1024-1031. doi: 10.12965/jer.1836488.244. https://doi.org/10.12965/jer.1836488.244

[19] Keay L, Praveen D, Salam A, et al. A mixed methods evaluation of yoga as a fall prevention strategy for older people in India. Pilot Feasibility Stud. 2018;4:74. doi: 10.1186/s40814-018-0264-x. https://doi.org/10.1186/s40814-018-0264-x

[20] Taylor D, Hale L, Schluter P, Waters DL, Binns EE, McCracken H, et al. effectiveness of tai chi as a communitybased falls prevention intervention: A randomized controlled trial. J Am Geriatr Soc. 2012;60(5):841-848. https:// doi.org/10.1016/j.jcgg.2013.05.002 